\title{
Refractometric Study on Binary, Ternary, and Quaternary Solutions Made by Water, Methanol, Ethanol, Glycerol, D-glucose Monohydrate (DGMH), Sucrose, and Sodium Chloride at $\mathrm{T}=\mathbf{2 9 3 . 1 5} \mathrm{K}$ and Atmospheric Pressure
}

\author{
Javad Nasiri $^{1}$, Farhoush Kiani ${ }^{1 *}$, Fardad Koohyar ${ }^{* 2,3}$ \\ ${ }^{1}$ Faculty of Science, Department of Chemistry, Islamic Azad University, Ayatollah Amoli Branch, Amol, Iran \\ ${ }^{2}$ Division of Computational Physics, Institute for Computational Science, Ton Duc Thang University, Ho Chi \\ Minh City, Vietnam \\ ${ }^{3}$ Faculty of Applied Sciences, Ton Duc Thang University, Ho Chi Minh City, Vietnam
}

* Corresponding authors: e-mail: fardadkoohyar@tdtu.edu.vn, Farhoush_kiani@yahoo.com

Received September 5 ${ }^{\text {th }}, 2018$; Accepted October 12 2018.

DOI: http://dx.doi.org/10.29356/jmcs.v62i4.679

\begin{abstract}
The glycerol, D-glucose monohydrate (DGMH), sucrose, and sodium chloride are used in food industries and the measurement of properties for these components and their aqueous solutions can be important. In this research work, the refractive indices for binary solutions of (methanol + glycerol), (ethanol + glycerol), ternary solutions of (water + glycerol + DGMH), (water + glycerol + sucrose $),($ water + sucrose + DGMH), (water + sucrose + ethanol), $($ water + ethanol + DGMH), $($ water $+\mathrm{NaCl}+\mathrm{DGMH}),($ water + methanol $+\mathrm{NaCl})$, $($ water + ethanol $+\mathrm{NaCl})$, $($ water $+\mathrm{NaCl}+$ glycerol), $($ water + sucrose $+\mathrm{NaCl})$, and quaternary solutions of (water + ethanol + sucrose + DGMH), (water + ethanol + sucrose + glycerol), $($ water $+\mathrm{NaCl}+$ sucrose + glycerol) were measured in wide range of mole fractions at $\mathrm{T}=293.15 \mathrm{~K}$ and atmospheric pressure. For binary solutions of this study, the changes of refractive index on mixing, $\Delta n_{\mathrm{D}}$, were calculated in each mole fraction at $\mathrm{T}=293.15 \mathrm{~K}$. Also, the refractive index of binary solutions was fitted by a semiempirical equation. The constant of this equation, $\mathrm{Kr}$, was introduced and suggested by Koohyar in 2018 . This constant can be used to investigate strength of interactions between solute and solvent molecules. For ternary and quaternary solutions of this study, a semi-empirical equation was used to determine refractive indices at given temperature. The comparison between calculated and experimental refractive indices shows that there is a good agreement between them especially in lower molal concentrations (diluted solution). In other words, linear behavior of the refractive index occurs only in the diluted solutions.

Keywords: Refractive index; solution; water; glycerol; D-glucose monohydrate (DGMH); sucrose; sodium chloride.

Resumen. El glicerol, D-glucosa monohidrato (DGMH), sacarosa y cloruro de sodio se utilizan en las industrias alimentarias y la medición de las propiedades de estos componentes y sus soluciones acuosas puede ser importante. En este trabajo de investigación, los índices de refracción para soluciones binarias de (metanol + glicerol), (etanol + glicerol), soluciones ternarias de (agua + glicerol + DGMH), (agua + glicerol + sacarosa), (agua + sacarosa + DGMH) $,($ agua + sacarosa + etanol $),($ agua + etanol $+\mathrm{DGMH}),($ agua $+\mathrm{NaCl}+$ $\mathrm{DGMH}),($ agua + metanol $+\mathrm{NaCl}),($ agua + etanol $+\mathrm{NaCl}),($ agua $+\mathrm{NaCl}+$ glicerol $),($ agua + sacarosa + $\mathrm{NaCl})$ y soluciones cuaternarias de $($ agua + etanol + sacarosa + DGMH), (agua + etanol + sacarosa + glicerol), (agua $+\mathrm{NaCl}+$ sacarosa + glicerol) se midieron en un amplio rango de fracciones molares en $\mathrm{T}=$ 293.15 K y presión atmosférica. Para las soluciones binarias de este estudio, los cambios del índice de refracción en la mezcla, $\mathrm{nD}$, se calcularon en cada fracción molar a $\mathrm{T}=293.15 \mathrm{~K}$. Además, el índice de refracción de las soluciones binarias se ajustó mediante una ecuación semi-empírica. La constante de esta ecuación, Kr, fue representada por Koohyar et al. en 2011. Esta constante se puede usar para investigar la fuerza de las interacciones entre las moléculas de soluto y solvente. Para las soluciones ternarias y
\end{abstract}


cuaternarias de este estudio, se utilizó una ecuación semi-empírica para determinar los índices de refracción a una temperatura dada. La comparación entre los índices de refracción calculados y experimentales muestra que existe una buena concordancia entre ellos, especialmente en concentraciones más bajas de molal (solución diluida). En otras palabras, el comportamiento lineal del índice de refracción ocurre solo en las soluciones diluidas

Palabras clave: Índice de refracción; solución; agua; glicerol; D-glucosa monohidratada (DGMH); sucrosa; cloruro de sodio.

\section{Introduction}

The refractive index is one of the most important thermodynamic properties of liquids and solutions. In various industries such as pharmaceutical, food, detergent and cosmetic, the reactions between species occur in solution phase. Therefore, the determination of thermodynamic properties of solutions (such as density, enthalpy, sound velocity, and refractive index) can help us to control production process in various industries [1-4].

When the light passes through a solution, some interactions occur between the photons of light and solvent-solute complexes and as a result, the speed of light decreases in this solution. For a solution, the refractive index can be obtained from below equation:

$$
n_{D}=c / v
$$

In above equation, $c$ and $v$ are the speed of light in vacuum and solution, respectively. Refractive index data have many usages in both industrial and research fields.

In an aqueous solution, a degree Brix $\left({ }^{\circ} \mathrm{Bx}\right)$ indicates the sugar content. One degree Brix shows that there is one gram of sucrose in 100 grams of solution. If the solution contains dissolved solids other than pure sucrose, then the ${ }^{\circ} \mathrm{Bx}$ only approximates the dissolved solid content. For aqueous solutions of sugars, there is a close relationship between the value of refractive index and its degree Brix [5-7]. The ${ }^{\circ} \mathrm{Bx}$ is usually used in the sugar, carbonated beverage, fruit juice, maple syrup and honey industries.

The refractive index can act as a detector and sensor. For instance, the refractive index can be used to detect and quantify the contamination of liquids such as drinking water and other beverages. The results show that the concentration of contamination increases linearly by increasing of refractive index [8].

The label-free detection and biosensing techniques for animal viruses have been developed in the recent years $[9,10]$. Among various designed biosensor, an increasing group of biosensors works with detecting the local change in the refractive index due to the presence of single or a few virus particles $[11,12]$. This type of optical biosensors include the optical interferometry [13,14], surface plasmon resonance [15,16], or the optical cavity resonance $[17,18]$. In these biosensors, the accurate refractive index for the viruses of interest is required to determine the size and concentration of viruses [19-21].

Another group of refractive index-based sensors have attractive specifications as non-destructive and universal detectors for liquid chromatographic separations, but a short dynamic range and sensitivity to minor thermal perturbations limit the utility of commercial refractive index detectors for many possible usages, especially those needs the use of gradient elution [22].

In 2007, Zhu et al. expanded a novel miniaturized and multiplexed, on-capillary, refractive index detector using liquid core optical ring resonators (LCORRs) for future development of capillary electrophoresis (CE) devices [23]. A glass capillary with a diameter of about 100 mum and a wall thickness of a few micrometers are applied in liquid-core optical ring-resonator sensors [24]. They are high-sensitivity label-free lab-on-a-chip biological-chemical sensor [25].

Voglibose is a strong glucosidase inhibitor that is used in treatment of type II diabetes mellitus. In pharmaceutical formulations, a rapid and simple HPLC method (high performance liquid chromatographic) with refractive index detection was developed to determine voglibose. The LOD and LOQ (limit of detection and quantification) were found to be 2.91 and $9.7 \mu \mathrm{g} / \mathrm{mL}$. This method could be successfully used for the quantification of voglibose in pharmaceutical formulations [26]. 
On the other hand, the refractive index can be used to estimate thermophysical properties of hydrocarbons and petroleum mixtures. Especially, the refractive index helps us to find out critical constants (critical temperature, critical pressure, critical density of a substance and etc), the composition of petroleum mixtures, and temperature-dependent properties like PVT, heat capacity, and transport properties of hydrocarbon fluids [27].

Most solute components that were used in this study (methanol, ethanol, glycerol, DGMH, and sucrose) are alcohol. These components are very soluble in water due to having one, two, three or more hydroxyl groups. Methanol and ethanol are used as a solvent in many cases. For instance, in pharmaceutical industries, methanol and ethanol may be applied in production of tablets and also during the film-coating process [28]. Methanol and ethanol can also be used as solvent in extraction of antioxidant phenolic compounds from coffee silverskin [29]. In addition, ethanol/water and methanol/water mixtures are applied as a solvent for synthesis of polydopamine nano-spheres using solubility parameter [30]. Glycerol is usually used in production of detergents and cosmetics [31,32]. DGMH and sucrose are widely used in various food industries.

In this study, we measured the refractive index for binary mixtures of (methanol + glycerol), (ethanol + glycerol) and also aqueous solutions of (glycerol + DGMH), (glycerol + sucrose), (sucrose + DGMH), (sucrose + ethanol), (ethanol $+\mathrm{DGMH}),(\mathrm{NaCl}+\mathrm{DGMH}),($ methanol $+\mathrm{NaCl}),($ ethanol $+\mathrm{NaCl}),(\mathrm{NaCl}+$ glycerol), (sucrose $+\mathrm{NaCl})$, (ethanol + sucrose $+\mathrm{DGMH})$, (ethanol + sucrose + glycerol), and $(\mathrm{NaCl}+$ sucrose + glycerol) at $\mathrm{T}=293.15 \mathrm{~K}$ and atmospheric pressure. The obtained data were listed in Table 1 .

Table 1. The values of refractive index, $n_{\mathrm{D}}$, and the changes of refractive index on mixing, $\Delta n_{\mathrm{D}}$, for binary solutions of (methanol + glycerol) and (ethanol + glycerol) in wide range of mole fractions, $x$, at $\mathrm{T}=293.15 \mathrm{~K}$ and atmospheric pressure.

\begin{tabular}{|c|c|c|c|c|c|c|c|}
\hline $\boldsymbol{x}_{\mathbf{1}}$ & $\boldsymbol{x}_{\mathbf{2}}$ & $\boldsymbol{n}_{\mathbf{D}}$ & $\Delta \boldsymbol{n}_{\mathbf{D}}$ & $\boldsymbol{x}_{\mathbf{1}}$ & $\boldsymbol{x}_{\mathbf{2}}$ & $\boldsymbol{n}_{\mathbf{D}}$ & $\Delta \boldsymbol{n}_{\mathbf{D}}$ \\
\hline \multicolumn{3}{|c|}{ methanol (1) + glycerol (2) } & \multicolumn{3}{|c|}{ ethanol (1) + glycerol (2) } \\
\hline 1.0000 & 0.0000 & 1.3290 & 0.00000 & 1.0000 & 0.0000 & 1.3614 & 0.00000 \\
\hline 0.9664 & 0.0336 & 1.3435 & 0.00963 & 0.9333 & 0.0667 & 1.3741 & 0.00519 \\
\hline 0.9607 & 0.0393 & 1.3490 & 0.01430 & 0.9230 & 0.0770 & 1.3775 & 0.00743 \\
\hline 0.9388 & 0.0612 & 1.3572 & 0.01933 & 0.8695 & 0.1305 & 1.3862 & 0.01011 \\
\hline 0.9096 & 0.0904 & 1.3682 & 0.02609 & 0.8181 & 0.1819 & 1.3941 & 0.01222 \\
\hline 0.8734 & 0.1266 & 1.3782 & 0.03084 & 0.7618 & 0.2382 & 1.4014 & 0.01318 \\
\hline 0.8273 & 0.1727 & 1.3882 & 0.03416 & 0.6999 & 0.3001 & 1.4102 & 0.01501 \\
\hline 0.7870 & 0.2130 & 1.3964 & 0.03652 & 0.6315 & 0.3685 & 1.4193 & 0.01641 \\
\hline 0.7419 & 0.2581 & 1.4050 & 0.03858 & 0.5554 & 0.4446 & 1.4285 & 0.01704 \\
\hline 0.6680 & 0.3320 & 1.4160 & 0.03886 & 0.4735 & 0.5265 & 1.4363 & 0.01562 \\
\hline 0.5897 & 0.4103 & 1.4263 & 0.03781 & 0.3999 & 0.6001 & 1.4425 & 0.01353 \\
\hline 0.5065 & 0.4935 & 1.4368 & 0.03625 & 0.3332 & 0.6668 & 1.4477 & 0.01122 \\
\hline 0.4034 & 0.5966 & 1.4490 & 0.03350 & 0.2608 & 0.7392 & 1.4535 & 0.00887 \\
\hline 0.3013 & 0.6987 & 1.4580 & 0.02770 & 0.1999 & 0.8001 & 1.4576 & 0.00612 \\
\hline 0.2000 & 0.8000 & 1.4654 & 0.02041 & 0.0000 & 1.0000 & 1.4740 & 0.00000 \\
\hline 0.0000 & 1.0000 & 1.4740 & 0.00000 & & & & \\
\hline
\end{tabular}

\section{Experimental}

\section{Materials}

The used chemicals of this study (methanol, ethanol, glycerol, DGMH, sucrose, and sodium chloride) were purchased from Merck Company. The purity of these chemicals was more 99 mass percent and 
they were used without further purification. The aqueous solutions of this study were prepared using the deionized water. Each solution was prepared from known masses of each chemical in air-tight stoppered glass bottles. In addition, each measurement was repeated three times and the average was reported.

Apparatus and procedure

All solutions were prepared by weighing suitable of the individual components and mixed in a beaker. A balance (precise $240 \mathrm{~A}$, Switzerland) was used to weigh the solutes with a precision of $\pm 0.0001 \mathrm{~g}$. The applied instrument was calibrated at atmospheric pressure with double distilled water before each series of measurement. The refractive index of solutions was determined using an Abbe reftactometer (CARL ZEISS, Model A, Germany). The uncertainties of the refractive index and temperature are \pm 0.0001 and \pm 0.01 $\mathrm{K}$, respectively.

\section{Results and discussion}

Eq. 1 shows that the refractive index of a solution increases when the speed of light decreases in this medium. When the light passes through an aqueous solution, the amount of reduction of light speed (and consequently, the increasing of refractive index) has direct relationship with the strength of interaction between solvent and solute molecules. The strength of interaction between these species can be affected by three factors [33]. The first factor is the molecular weight of solute. As we know, for a solute molecule, the molecular weight shows the total number of electrons and protons of this molecule. The electrons and protons of a molecule generate electrical fields. In addition, the moving electrons generate magnetic fields. The strength of resultant of these electrical and magnetic fields increases as the number of electron and proton (molecular weight) increases. The solute molecule with stronger electrical and magnetic field generates stronger interaction with solvent molecule. Therefore, in an aqueous solution, the strength of interaction between solute and solvent molecules increases by increasing of solute molecular weight.

The second factor is the agents that are attached to solute molecules. If an electron donor agent is attached to a solute molecule, the electron density in solute molecules increases and then, the strength of interaction between solute and solvent molecules increases. If an electron acceptor agent is attached to a solute molecule, the electron density in solute molecules decreases and then, the strength of interaction between solute and solvent molecules decreases.

The third factor is the shape and size of solute molecules. In some cases, solute or solvent molecules with smaller size can be better located in solute-solvent complex. In this condition, the strength of interaction between solute and solvent molecules increases.

The above three factors can be effective on value of refractive index of liquid solutions. The fourth factor that affects on value of refractive index of liquid solutions is concentration. In 2011, Koohyar suggested the below linear equation to fit refractive index of liquid solutions at constant temperature and pressure [33]:

$$
n_{\mathrm{D}}=K_{\mathrm{r}} c+n_{\mathrm{o}}
$$

In Eq. $2, n_{\mathrm{D}}$ is the refractive index of a solution, $n_{\mathrm{o}}$ is the refractive index of solvent, and $c$ is the concentration of solute. The value of $K_{\mathrm{r}}$ shows the strength of interaction between solute and solvent molecules. The higher value of $K_{\mathrm{r}}$ shows the stronger interaction between solute and solvent molecules. Therefore, in liquid solutions, three above mentioned factors (molecular weight, attached agents, and also shape and size of solute or solvent molecule) are effective in the value of $K_{\mathrm{r}}$ [34].

In 2018, Koohyar showed that Eq. 2 can be successfully applied to predict the refractive index of binary aqueous solutions for alkane polyols $\left[\mathrm{R}(\mathrm{OH})_{\mathrm{n}}, \mathrm{n}=2\right.$ to $\left.6-\mathrm{OH}, \mathrm{s}\right)$ and also polyols with one ring (monosaccharide) [34]. In addition, in this research work, Koohyar introduced the below equation to calculate the values of $K_{\mathrm{r}}$ for aqueous solutions of alkane polyols $\left[\mathrm{R}(\mathrm{OH})_{\mathrm{n}}, \mathrm{n}=2\right.$ to $\left.6-\mathrm{OH}, \mathrm{s}\right)$ and also polyols with one ring (monosaccharide) [34]:

$$
K_{\text {ref }}=\left[M_{\text {w(solute })}-18.01\right]\left[\left(5.2 \times 10^{-6}\right) N_{(-\mathrm{O}-)}+\left(1.28 \times 10^{-4}\right)\right]
$$


In Eq. 3, $M_{\mathrm{w}}$ is the molecular weight of solute and $N_{(-\mathrm{O}-)}$ is the number of hydroxyl groups and/or oxygen atoms that are existed in solute molecule. The first factor $\left[M_{\mathrm{w}(\text { solute) }}\right]$ and second factor [attached agents: $\left.N_{(-\mathrm{OH})}\right]$ that are effective in strength of interaction between solute-solvent molecules can be obviously seen in Eq. 3.

On the other hand, Koohyar stated that Eq. 2 can be re-written as Eqs. 4 and 5 for ternary and quaternary aqueous solutions, respectively [34]:

$$
\begin{aligned}
& n_{\mathrm{D}}=K_{\mathrm{r}(1)} c_{1}+K_{\mathrm{r}(2)} c_{2}+n_{\mathrm{o}} \\
& n_{\mathrm{D}}=K_{\mathrm{r}(1)} c_{1}+K_{\mathrm{r}(2) c_{2}}+K_{\mathrm{r}(3) c_{3}}+n_{\mathrm{o}}
\end{aligned}
$$

In Eqs. 4 and 5, (1), (2), and (3) implies to solute No. 1, solute No. 2, and solute No. 3, respectively. $n_{\mathrm{o}}$ is the refractive index of solvent (water).

\section{Study on binary solutions}

In this work, the binary solutions of [methanol (1) + glycerol (2)] and [ethanol (1) + glycerol (2)] were studied. The experimental values of refractive index for these solutions are listed in Table 1. Methanol, ethanol, and glycerol are alcohols. Glycerol has three hydroxyl groups and is miscible in water, ethanol, and methanol. The value of $K_{\text {ref }}$ for glycerol in methanol and ethanol solutions can be obtained by using Eq. 2 . Fig. 1 shows that the values of $K_{\text {ref }}$ for glycerol in methanol and ethanol solutions are $0.0081 \mathrm{~L} / \mathrm{mol}$ and $0.0040 \mathrm{~L} / \mathrm{mol}$, respectively, at $\mathrm{T}=293.15 \mathrm{~K}$ and atmospheric pressure. In addition, the value of $K_{\text {ref }}$ for glycerol in aqueous solution is $0.0106 \mathrm{~L} / \mathrm{mol}$ [35]. Therefore, the below order can be seen about values of $K_{\text {ref }}$ for glycerol in methanol, ethanol, and aqueous solutions at $\mathrm{T}=293.15 \mathrm{~K}$ and atmospheric pressure:

$$
K_{\text {ref (water }+ \text { glycerol })}>K_{\text {ref (methanol + glycerol })}>K_{\text {ref (ethanol + glycerol) }}
$$

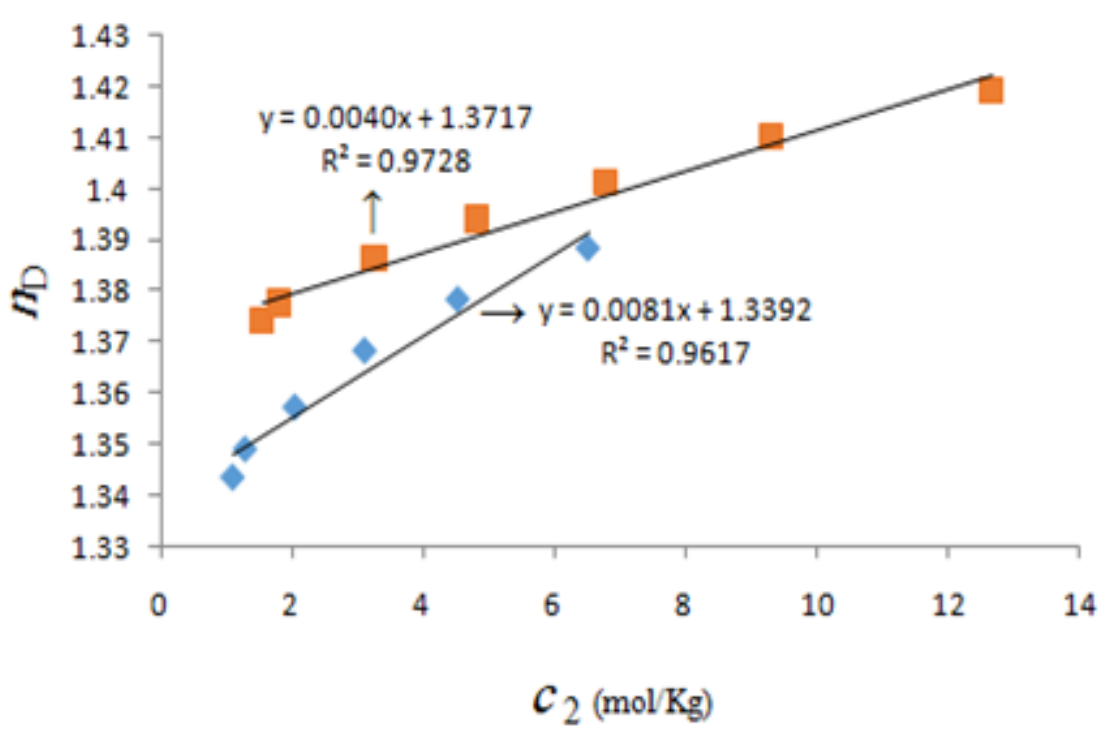

Fig. 1. The refractive index, $n_{\mathrm{D}}$, plotted against molal concentration of solute, $c_{2}$, for binary solutions of ( $\left.\downarrow\right)$ : [methanol (1) + glycerol (2)] and ( $\mathbf{a})$ : [ethanol (1) + glycerol (2)] at T $=293.15 \mathrm{~K}$.

The value of $K_{\mathrm{r}}$ shows the strength of interaction between solute and solvent molecules. The relation 6 shows that the interaction between glycerol and water molecules is stronger than interaction between glycerol and methanol molecules and also, interaction between glycerol and methanol molecules is stronger than interaction between glycerol and ethanol molecules. This subject can also be seen in Fig. 2. In this figure, 
the change of refractive indices on mixing, $\Delta n_{\mathrm{D}}$, were plotted against mole fraction of glycerol, $x_{2}$, for binary solutions of [ethanol (1) + glycerol (2)], [methanol (1) + glycerol (2)], and [water (1) + glycerol (2)] at T = $293.15 \mathrm{~K}$.

For liquid binary solutions, the value of change of refractive index on mixing $\left(\Delta n_{\mathrm{D}}\right)$ is calculated using the below equation [36]:

$$
\Delta n_{D}=n_{D}-\left(x_{1} n_{D 1}+x_{2} n_{D 2}\right)
$$

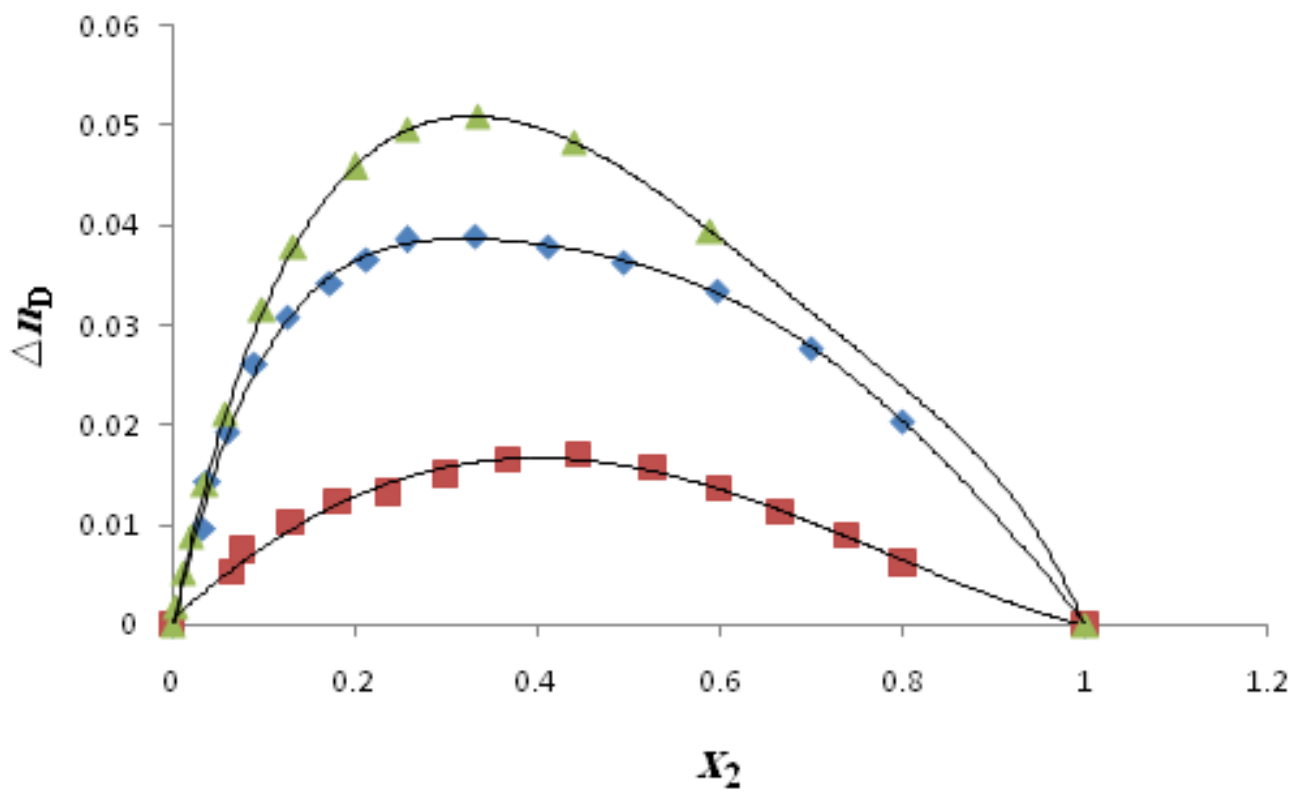

Fig. 2. The change of refractive index on mixing, $\Delta n_{\mathrm{D}}$, plotted against mole fraction of solute, $x_{2}$, for binary

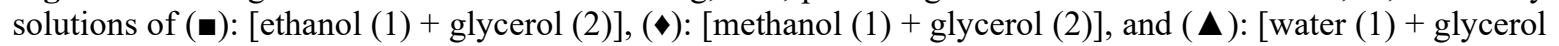
(2)] at $\mathrm{T}=293.15 \mathrm{~K}$ (for aqueous solution of glycerol, data were obtained from Ref. [35]).

Where $x_{1}$ and $x_{2}$ are mole fractions of solute and solvent, respectively, $n_{\mathrm{D} 1}$ and $n_{\mathrm{D} 2}$ are refractive index of solute and solvent, respectively and also, $n_{\mathrm{D}}$ is the refractive index of binary solution. The values of $\Delta n_{\mathrm{D}}$ for binary solutions of this study, at $\mathrm{T}=293.15 \mathrm{~K}$, were calculated and listed in Table 1 . As it can be seen in Table 1, the sign of $\Delta n_{\mathrm{D}}$ for binary solutions of this study, in all mole fractions, is positive. It can show that in these solutions, the interaction between solute and solvent molecules is stronger than interaction between solute-solute and solvent-solvent molecules. Also, Fig. 2 shows the below order for values of $\Delta n_{\mathrm{D}}$ for glycerol in methanol, ethanol, and aqueous solutions at $\mathrm{T}=293.15 \mathrm{~K}$ and atmospheric pressure:

$$
\Delta n_{\mathrm{D}(\text { water }+ \text { glycerol })}>\Delta n_{\mathrm{D}(\text { methanol }+ \text { glycerol })}>\Delta n_{\mathrm{D}(\text { ethanol }+ \text { glycerol })}
$$

The value of $\Delta n_{\mathrm{D}}$ has direct relationship with strength of interaction between solute and solvent molecules. Therefore, we can state that the interaction between glycerol and water is stronger than interaction between glycerol and methanol and also, interaction between glycerol and methanol is stronger than interaction between glycerol and ethanol. This result has also been achieved according to relation 6. It is well know that the water molecule is smaller than the methanol molecule and also, the methanol molecule is smaller than the ethanol molecule. Molecule with smaller size can be easier (and/or better) placed in solutesolvent complex and in this situation, the interaction between solute and solvent molecules will be stronger. The Redlich-Kister polynomial equation is applied to fit $\Delta n_{\mathrm{D}}$ data as the below [37]: 


$$
Y=x_{2}\left(1-x_{2}\right) \sum_{i=0}^{n} A_{i}\left(2 x_{2}-1\right)^{i}
$$

In the above equation, $x_{2}$ is the mole fraction of solute, $Y$ is thermodynamic properties and $A_{\mathrm{i}}$ is adjustable parameter.

The optimum number of coefficients $A_{\mathrm{i}}$ was calculated using an examination of the variation of the standard deviation [38]:

$$
\delta_{Y}=\left[\frac{\sum\left(Y_{(c a l)}-Y_{(\text {exp })}\right)^{2}}{n-m}\right]^{1 / 2}
$$

Where, $\mathrm{n}$ is the total number of experimental values and $\mathrm{m}$ is the number of parameters.

The value of Redlich-Kister parameters $\left(A_{\mathrm{i}}\right)$ along with the standard deviation $(\delta)$ for $\Delta n_{\mathrm{D}}$ of binary solutions of this study were listed in Table 2 .

Table 2. The Redlich-Kister polynomial equation constants $\left(A_{\mathrm{i}}\right)$ along with the standard deviation $(\delta)$ for $\Delta n_{\mathrm{D}}$ of binary solutions made by methanol, ethanol, and glycerol at $\mathrm{T}=293.15 \mathrm{~K}$.

\begin{tabular}{|c|c|c|c|c|c|}
\hline $\boldsymbol{A}_{\mathbf{0}}$ & $\boldsymbol{A}_{\mathbf{1}}$ & $\boldsymbol{A}_{\mathbf{2}}$ & $\boldsymbol{A}_{\mathbf{3}}$ & $\boldsymbol{A}_{\mathbf{4}}$ & $\boldsymbol{\delta}$ \\
\hline \multicolumn{7}{|c|}{ methanol (1) + glycerol (2) } \\
\hline 0.34488 & -0.04863 & 0.07338 & -0.09887 & 0.04900 & 0.000967 \\
\hline \multicolumn{7}{|c|}{ ethanol (1) + glycerol (2) } \\
\hline 0.08156 & -0.02962 & -0.03675 & -0.00837 & 0.05694 & 0.000664 \\
\hline
\end{tabular}

\section{Study on ternary solutions}

As it has been previously mentioned in this article, four factors are effective on the value of refractive index of a liquid solution. These factors are molecular weight of solute, type of agents and groups which are attached to solute molecule, shape and size of solute molecule, and concentration of solutes.

In this research work, the refractive indices of ten ternary solutions (made by water, methanol, ethanol, glycerol, D-glucose monohydrate $(\mathrm{DGMH})$, sucrose, and sodium chloride) were determined at $\mathrm{T}=$ 293.15 K and atmospheric pressure. These data are listed in Table 3. As it can be seen in Table 3, among these solutions, the aqueous solutions of (glycerol + sucrose) and (sucrose + DGMH) have maximum values of refractive index. In this case, the first factor (molecular weight of solutes) is effective. These two aqueous solutions have solutes with highest molecular weight (sucrose, DGMH, and glycerol) among various ternary solutions of this study. In addition, the maximum value of refractive index for aqueous solution of (glycerol + sucrose) is more than that one for aqueous solution of (sucrose + DGMH). In this case, the fourth factor (the sum of molal concentration of solutes) is effective. The sum of molal concentration of solutes for solutions of (water + glycerol + sucrose) and (water + sucrose + DGMH) are 7.4910 and 4.6478, respectively.

Also, among various ternary solutions of this study, aqueous solutions of (methanol $+\mathrm{NaCl}$ ) and (ethanol $+\mathrm{NaCl}$ ) have minimum value of refractive index. These two aqueous solutions have solutes with lowest molecular weight (methanol, ethanol, and $\mathrm{NaCl}$ ) among various ternary solutions of this study.

We applied Eq. 4 to predict the refractive index $\left[n_{\mathrm{D}(\mathrm{calc})}\right]$ for ternary solutions of this study (please see Table 3) at $\mathrm{T}=293.15 \mathrm{~K}$. The values of $K_{\mathrm{r}(1)}$ and $K_{\mathrm{r}(2)}$ can be obtained by plotting refractive index of aqueous solution of solute No. 1 and solute No. 2, respectively, versus molal concentration (according Eq. 2). The values of $K_{\mathrm{r}}$ for various solutes of this study were obtained at $\mathrm{T}=293.15 \mathrm{~K}$ [35] and the results are shown in Fig. 3. Of course, in this study, the values of $K_{\mathrm{r}}$ were obtained based on molal concentration. In some other research works, the values of $K_{\mathrm{r}}$ were obtained based on molar concentrations [33,34,36]. Using $K_{\mathrm{r}}, \mathrm{s}$ (Fig. 3), we can write Eq. 4 for each ternary solution of this study. Fig. 4 represents Eq. 4 as well as the chart of refractive index versus molal concentration of solutes $\left(c_{2}\right.$ and $\left.c_{3}\right)$ for each ternary solution of this study. 


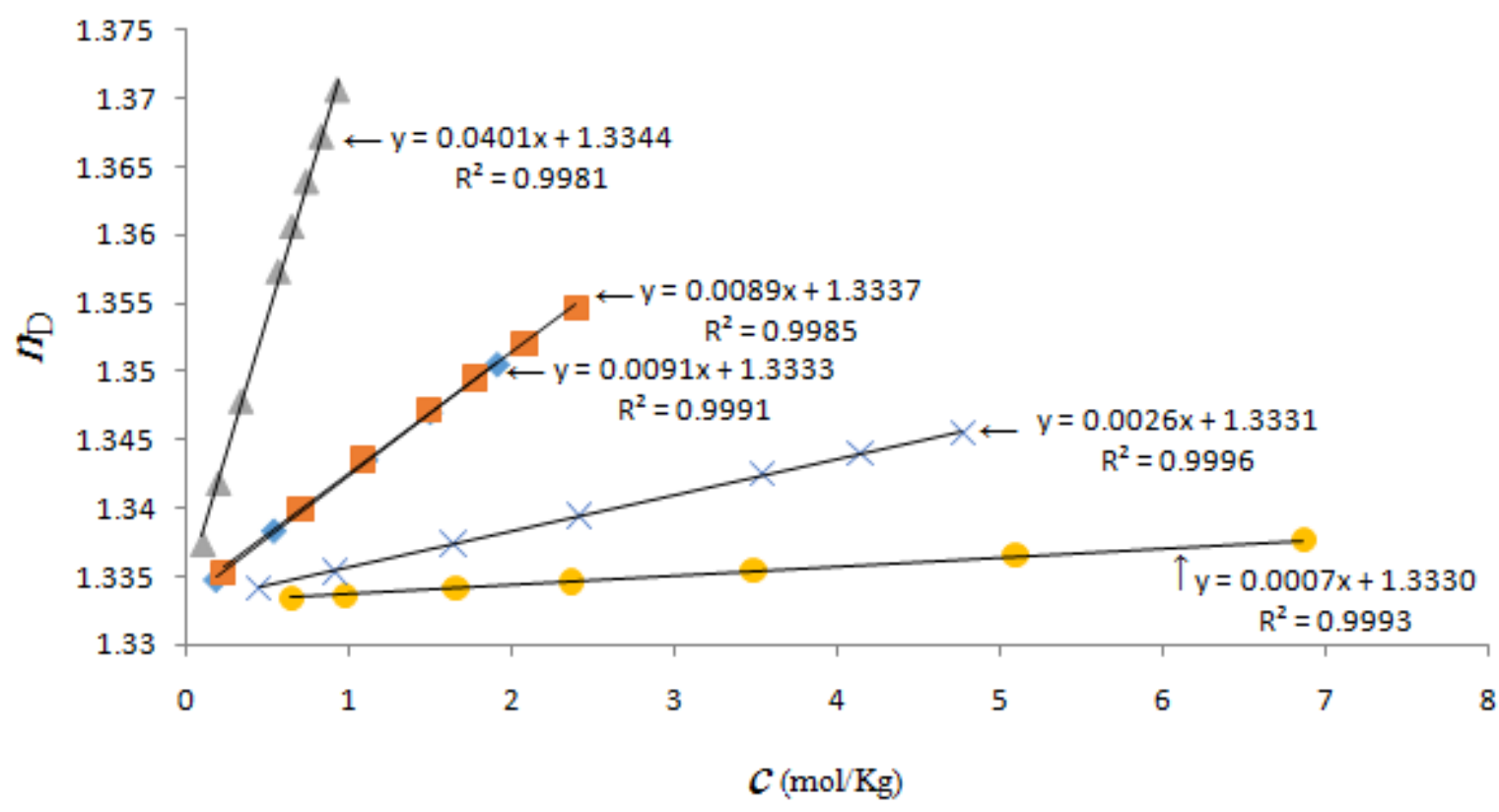

Fig. 3. Refractive index plotted against molal concentration of solute, $c$, for aqueous solutions of $(\mathbf{\Delta})$ : sucrose, $(\bullet)$ : chloride sodium, $(\boldsymbol{\bullet})$ : glycerol, $(\times)$ : ethanol, and $(\bullet)$ : methanol at T $=293.15 \mathrm{~K}$ (Data obtained from Ref. [35]).

In Table 3, we compared the experimental and calculated refractive indices (using Eq. 4) for ternary solutions of this study. Table 3 shows that in most cases, in low concentration (diluted solution) the R.C is excellent and good. In addition, the R.C in middle molal concentrations is acceptable. These results indicate that Eq. 4 can be successfully used for calculating refractive index of these aqueous solutions especially in low (diluted solution) and middle molal concentrations.

In higher molal concentrations, the solute-solute interactions increase and therefore, the solutesolvent interactions decrease. As it can be seen On the other hand, it was observed that Eq. 4 can be applied in more range of concentration for solutions which have sodium chloride. It seems that ionic component $(\mathrm{NaCl})$ is effective in this case. It is clear that in same molecular weights, the interaction between ionic component and water is stronger than interaction between neutral component and water. 
Article
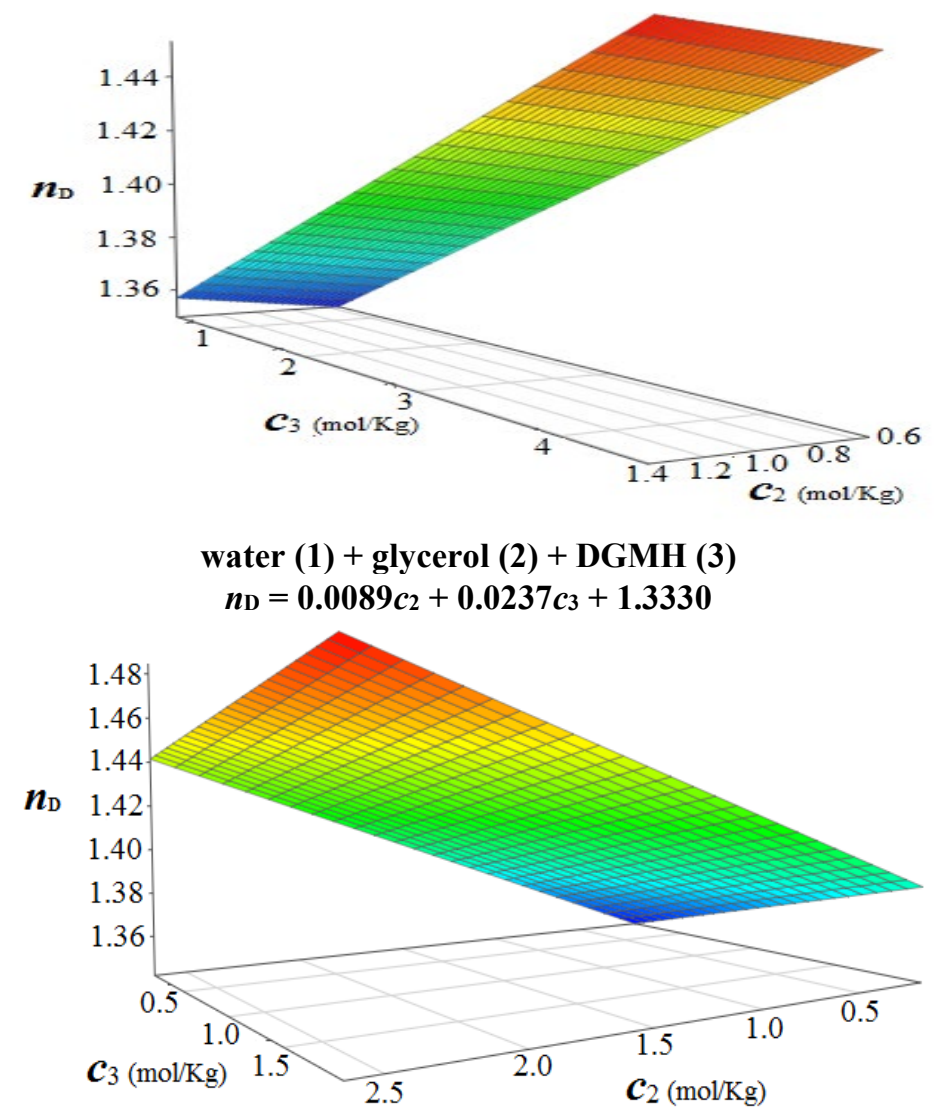

water (1) + sucrose (2) + DGMH (3)

$n_{\mathrm{D}}=0.0401 c_{2}+0.0237 c_{3}+1.3330$

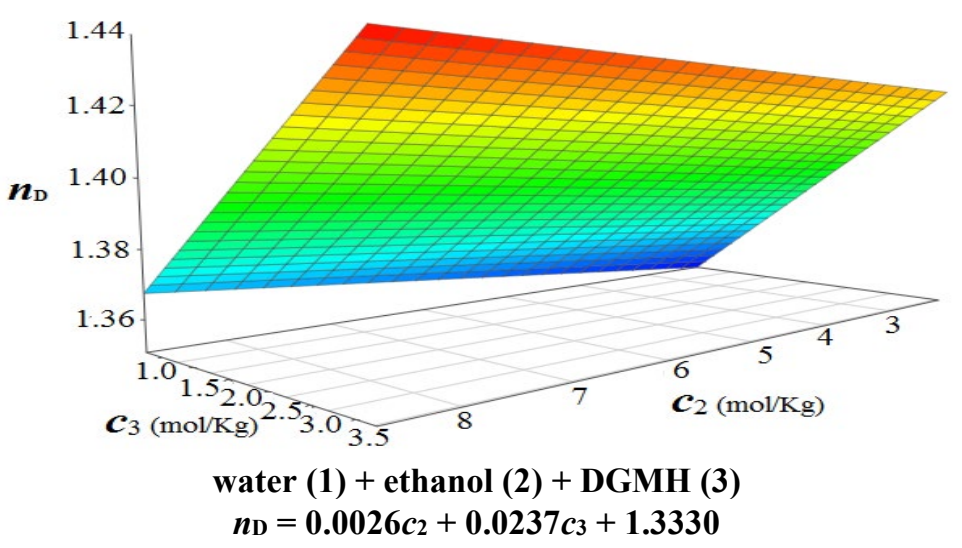

J. Mex. Chem. Soc. 2018, 62(4)

(C)2018, Sociedad Química de México

ISSN-e 2594-0317

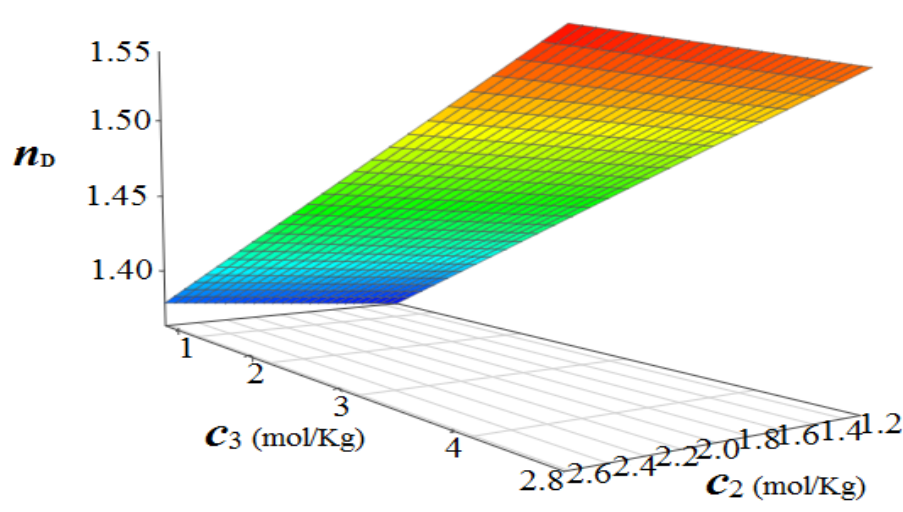

water (1) + glycerol (2) + sucrose (3)

$n_{\mathrm{D}}=0.0089 c_{2}+0.0401 c_{3}+1.3330$

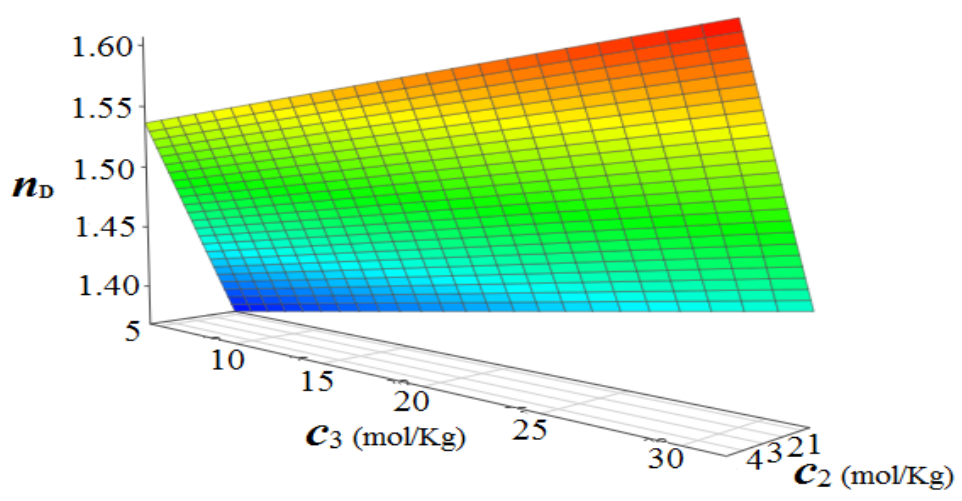

water (1) + sucrose (2) + ethanol (3)

$n_{\mathrm{D}}=0.0401 c_{2}+0.0026 c_{3}+1.3330$

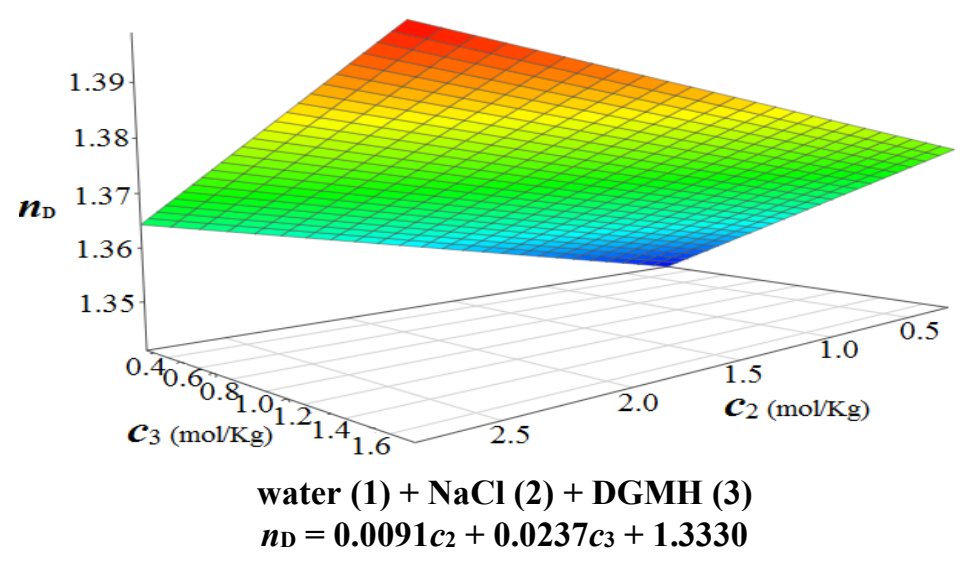



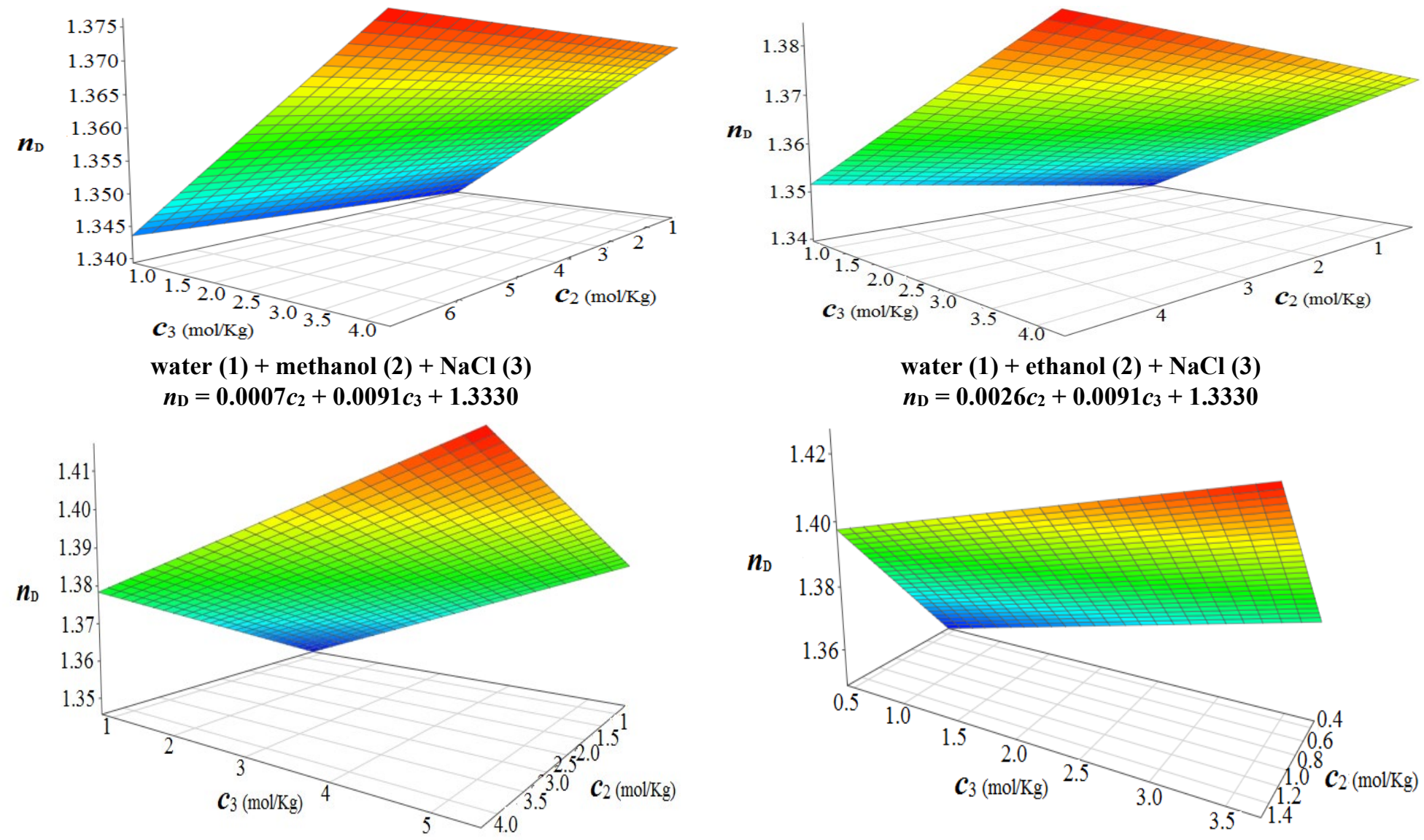

water (1) + NaCl (2) + glycerol (3)

water (1) + sucrose (2) + $\mathrm{NaCl}(3)$

$n_{\mathrm{D}}=0.0091 c_{2}+0.0089 c_{3}+1.3330$

$n_{\mathrm{D}}=0.0401 c_{2}+0.0091 c_{3}+1.3330$

Fig. 4. Plotting of refractive index, $n_{\mathrm{D}}$, versus molal concentration of solutes, $c_{2}$ and $c_{3}$, (according to Eq. 3 ) for various ternary aqueous solutions made by $\mathrm{D}-(+)$-glucose monohydrate (DGMH), sucrose, glycerol, ethanol, methanol, and sodium chloride $(\mathrm{NaCl})$ at $\mathrm{T}=293.15 \mathrm{~K}$.

\section{Study on quaternary solutions}

The refractive indices for aqueous solutions of (ethanol + sucrose + DGMH), (ethanol + sucrose + glycerol), and $(\mathrm{NaCl}+$ sucrose + glycerol) were determined at $\mathrm{T}=293.15 \mathrm{~K}$ and atmospheric pressure. These data were listed in Table 4. Among these three solutions, the aqueous solution of (ethanol + sucrose + glycerol) has maximum value of refractive index (1.4232). It can be due to have the highest concentration of solutes $\left(c_{2}+c_{3}+c_{4}=15.7283\right)$. In this case, fourth factor is more effective.

Eq. 5 was applied to calculate refractive index of quaternary solutions of this study. Calculated refractive indices $\left[n_{\mathrm{D}(\mathrm{calc})}\right]$ were shown in Table 4 . As it can be seen in this table, the results of comparison (R.C) between experimentally determined refractive index $\left[n_{\mathrm{D}(\exp )}\right]$ and calculated refractive index [ $\left.n_{\mathrm{D}(\mathrm{calc})}\right]$, using Eq. 5, are excellent, good, and acceptable. These results show that Eq. 5 can be successfully applied to calculate refractive index of these aqueous solutions especially in low (diluted solution) and middle molal concentrations.

In addition, as it can be seen in Table 4 , in aqueous solution of $(\mathrm{NaCl}+$ sucrose + glycerol), compared to other quaternary solutions of this study, Eq. 5 can be applied in more range of molal concentration to predict the refractive index. 
Table 3. The experimental and theoretical (obtained from Eq. 4) values of refractive index, $n_{\mathrm{D}}$, along with the comparison between them, R.C, for different ternary solutions made by water, D- $(+)$-glucose monohydrate $(\mathrm{DGMH})$, sucrose, glycerol, ethanol, methanol, and sodium chloride $(\mathrm{NaCl})$ in wide range of mole fraction, $x_{2}$, and molal concentrations, $c$, at $\mathrm{T}=293.15 \mathrm{~K}$ and atmospheric pressure.

\begin{tabular}{|c|c|c|c|c|c|c|}
\hline$x_{2}$ & $\begin{array}{c}c_{2} \\
\text { mol. } \mathrm{Kg}^{-1}\end{array}$ & $\begin{array}{c}c_{3} \\
\text { mol. } \mathrm{Kg}^{-1}\end{array}$ & $n_{\mathrm{D}(\exp )}$ & $n_{\mathrm{D}(\mathrm{calc})}$ & $\left(\Delta \boldsymbol{n}_{\mathbf{D}}\right)^{\mathrm{a}}$ & $R \cdot C^{b}$ \\
\hline \multicolumn{7}{|c|}{ water (1) + glycerol (2) + DGMH (3) } \\
\hline 0.0096 & 0.5429 & 0.5046 & 1.3506 & 1.3498 & 0.0008 & $\mathrm{E}$ \\
\hline 0.0105 & 0.5972 & 0.7569 & 1.3552 & 1.3563 & 0.0011 & $\mathrm{G}$ \\
\hline 0.0114 & 0.6515 & 1.0092 & 1.3627 & 1.3627 & 0.0000 & $\mathrm{E}$ \\
\hline 0.0123 & 0.7058 & 1.2615 & 1.3662 & 1.3692 & 0.0030 & Ac \\
\hline 0.0132 & 0.7601 & 1.5139 & 1.3727 & 1.3756 & 0.0029 & $\mathrm{Ac}$ \\
\hline 0.0140 & 0.8144 & 1.7662 & 1.3772 & 1.3821 & 0.0049 & Ac \\
\hline 0.0149 & 0.8687 & 2.0185 & 1.3782 & 1.3886 & 0.0104 & N.Ac \\
\hline 0.0157 & 0.9230 & 2.3969 & 1.3832 & 1.3980 & 0.0148 & N.Ac \\
\hline 0.0165 & 0.9773 & 2.7754 & 1.3892 & 1.4075 & 0.0183 & N.Ac \\
\hline 0.0173 & 1.0316 & 3.1539 & 1.3937 & 1.4169 & 0.0232 & N.Ac \\
\hline 0.0181 & 1.0859 & 3.5323 & 1.3982 & 1.4264 & 0.0282 & N.Ac \\
\hline 0.0197 & 1.1945 & 3.9108 & 1.4022 & 1.4363 & 0.0341 & N.Ac \\
\hline 0.0213 & 1.3031 & 4.2892 & 1.4062 & 1.4463 & 0.0401 & N.Ac \\
\hline 0.0229 & 1.4117 & 4.6677 & 1.4102 & 1.4562 & 0.0460 & N.Ac \\
\hline \multicolumn{7}{|c|}{ water (1) + glycerol (2) + sucrose (3) } \\
\hline 0.0190 & 1.0859 & 0.5046 & 1.3642 & 1.3629 & 0.0013 & $\mathrm{G}$ \\
\hline 0.0208 & 1.1945 & 0.7569 & 1.3755 & 1.3740 & 0.0015 & $\mathrm{G}$ \\
\hline 0.0225 & 1.3031 & 1.0092 & 1.3860 & 1.3851 & 0.0009 & $\mathrm{E}$ \\
\hline 0.0242 & 1.4117 & 1.2615 & 1.3932 & 1.3962 & 0.0030 & Ac \\
\hline 0.0259 & 1.5203 & 1.5139 & 1.4029 & 1.4072 & 0.0043 & $\mathrm{Ac}$ \\
\hline 0.0275 & 1.6288 & 1.7662 & 1.4134 & 1.4183 & 0.0049 & Ac \\
\hline 0.0292 & 1.7374 & 2.0185 & 1.4122 & 1.4294 & 0.0172 & N.Ac \\
\hline 0.0307 & 1.8460 & 2.3969 & 1.4193 & 1.4455 & 0.0262 & N.Ac \\
\hline 0.0322 & 1.9546 & 2.7754 & 1.4268 & 1.4617 & 0.0349 & N.Ac \\
\hline 0.0337 & 2.0632 & 3.1539 & 1.4337 & 1.4778 & 0.0441 & N.Ac \\
\hline 0.0352 & 2.1718 & 3.5323 & 1.4392 & 1.4940 & 0.0548 & N.Ac \\
\hline 0.0383 & 2.3890 & 3.9108 & 1.4462 & 1.5111 & 0.0649 & N.Ac \\
\hline 0.0413 & 2.6061 & 4.2892 & 1.4542 & 1.5282 & 0.0740 & N.Ac \\
\hline 0.0443 & 2.8233 & 4.6677 & 1.4582 & 1.5453 & 0.0871 & N.Ac \\
\hline \multicolumn{7}{|c|}{ water (1) + sucrose (2) + DGMH (3) } \\
\hline 0.0026 & 0.1461 & 0.1262 & 1.3427 & 1.3418 & 0.0009 & $\mathrm{E}$ \\
\hline 0.0052 & 0.2921 & 0.2523 & 1.3513 & 1.3507 & 0.0006 & $\mathrm{E}$ \\
\hline 0.0078 & 0.4382 & 0.3785 & 1.3586 & 1.3595 & 0.0009 & $\mathrm{E}$ \\
\hline 0.0103 & 0.5843 & 0.5046 & 1.3665 & 1.3684 & 0.0019 & $\mathrm{G}$ \\
\hline 0.0128 & 0.7304 & 0.6308 & 1.3737 & 1.3772 & 0.0035 & Ac \\
\hline 0.0153 & 0.8764 & 0.7569 & 1.3811 & 1.3861 & 0.0050 & Ac \\
\hline 0.0178 & 1.0225 & 0.8831 & 1.3852 & 1.3949 & 0.0097 & N.Ac \\
\hline 0.0203 & 1.1686 & 1.0092 & 1.3911 & 1.4038 & 0.0127 & N.Ac \\
\hline
\end{tabular}




\begin{tabular}{|c|c|c|c|c|c|c|}
\hline 0.0227 & 1.3146 & 1.1354 & 1.3961 & 1.4126 & 0.0165 & N.Ac \\
\hline 0.0251 & 1.4607 & 1.2615 & 1.4011 & 1.4215 & 0.0204 & N.Ac \\
\hline 0.0299 & 1.7528 & 1.3877 & 1.4092 & 1.4362 & 0.0270 & N.Ac \\
\hline 0.0346 & 2.045 & 1.5139 & 1.4151 & 1.4509 & 0.0358 & N.Ac \\
\hline 0.0392 & 2.3371 & 1.7662 & 1.4231 & 1.4686 & 0.0455 & N.Ac \\
\hline 0.0437 & 2.6293 & 2.0185 & 1.4321 & 1.4863 & 0.0542 & N.Ac \\
\hline \multicolumn{7}{|c|}{ water (1) + sucrose (2) + ethanol (3) } \\
\hline 0.0097 & 0.5843 & 4.3412 & 1.3636 & 1.3677 & 0.0041 & Ac \\
\hline 0.0139 & 0.8764 & 6.5118 & 1.3778 & 1.3851 & 0.0073 & Ac \\
\hline 0.0179 & 1.1686 & 8.6824 & 1.3808 & 1.4024 & 0.0216 & N.Ac \\
\hline 0.0215 & 1.4607 & 10.853 & 1.3861 & 1.4198 & 0.0337 & N.Ac \\
\hline 0.0249 & 1.7528 & 13.0237 & 1.3901 & 1.4371 & 0.0470 & N.Ac \\
\hline 0.0281 & 2.0450 & 15.1943 & 1.3942 & 1.4545 & 0.0603 & N.Ac \\
\hline 0.0311 & 2.3371 & 17.3649 & 1.3975 & 1.4719 & 0.0744 & N.Ac \\
\hline 0.0339 & 2.6293 & 19.5355 & 1.4001 & 1.4892 & 0.0891 & N.Ac \\
\hline 0.0365 & 2.9214 & 21.7061 & 1.4028 & 1.5066 & 0.1038 & N.Ac \\
\hline 0.0389 & 3.2136 & 23.8767 & 1.4050 & 1.5239 & 0.1189 & N.Ac \\
\hline 0.0429 & 3.6518 & 26.0473 & 1.4074 & 1.5472 & 0.1398 & N.Ac \\
\hline 0.0466 & 4.0900 & 28.2179 & 1.4095 & 1.5704 & 0.1609 & N.Ac \\
\hline 0.0501 & 4.5282 & 30.3885 & 1.4114 & 1.5936 & 0.1822 & N.Ac \\
\hline 0.0534 & 4.9664 & 32.5591 & 1.4132 & 1.6168 & 0.2036 & N.Ac \\
\hline \multicolumn{7}{|c|}{ water (1) + ethanol (2) + DGMH (3) } \\
\hline 0.0373 & 2.1706 & 0.5046 & 1.3485 & 1.3506 & 0.0021 & Ac \\
\hline 0.0460 & 2.7133 & 0.7569 & 1.3540 & 1.3580 & 0.0040 & Ac \\
\hline 0.0545 & 3.2559 & 1.0092 & 1.3608 & 1.3654 & 0.0046 & Ac \\
\hline 0.0627 & 3.7986 & 1.2615 & 1.3679 & 1.3728 & 0.0049 & Ac \\
\hline 0.0708 & 4.3412 & 1.5139 & 1.3672 & 1.3802 & 0.0130 & N.Ac \\
\hline 0.0786 & 4.8839 & 1.7662 & 1.3708 & 1.3876 & 0.0168 & N.Ac \\
\hline 0.0862 & 5.4265 & 2.0185 & 1.3752 & 1.3949 & 0.0197 & N.Ac \\
\hline 0.0937 & 5.9692 & 2.2708 & 1.3785 & 1.4023 & 0.0238 & N.Ac \\
\hline 0.1009 & 6.5118 & 2.5231 & 1.3814 & 1.4097 & 0.0283 & N.Ac \\
\hline 0.1080 & 7.0545 & 2.7754 & 1.3836 & 1.4171 & 0.0335 & N.Ac \\
\hline 0.1149 & 7.5971 & 3.0277 & 1.3867 & 1.4245 & 0.0378 & N.Ac \\
\hline 0.1216 & 8.1398 & 3.2800 & 1.3902 & 1.4319 & 0.0417 & N.Ac \\
\hline 0.1282 & 8.6824 & 3.5323 & 1.3930 & 1.4393 & 0.0463 & N.Ac \\
\hline \multicolumn{7}{|c|}{ water (1) + NaCl (2) + DGMH (3) } \\
\hline 0.0038 & 0.2140 & 0.2523 & 1.3415 & 1.3409 & 0.0006 & E \\
\hline 0.0076 & 0.4281 & 0.3785 & 1.3465 & 1.3459 & 0.0006 & E \\
\hline 0.0113 & 0.6421 & 0.5046 & 1.3515 & 1.3508 & 0.0007 & $\mathrm{E}$ \\
\hline 0.0150 & 0.8562 & 0.6308 & 1.3600 & 1.3557 & 0.0043 & $\mathrm{Ac}$ \\
\hline 0.0187 & 1.0702 & 0.7569 & 1.3635 & 1.3607 & 0.0028 & $\mathrm{Ac}$ \\
\hline 0.0223 & 1.2842 & 0.8831 & 1.3675 & 1.3656 & 0.0019 & $\mathrm{G}$ \\
\hline 0.0258 & 1.4983 & 1.0092 & 1.3715 & 1.3706 & 0.0009 & $E$ \\
\hline
\end{tabular}




\begin{tabular}{|c|c|c|c|c|c|c|}
\hline 0.0294 & 1.7123 & 1.1354 & 1.3745 & 1.3755 & 0.0010 & E \\
\hline 0.0328 & 1.9264 & 1.2615 & 1.3780 & 1.3804 & 0.0024 & Ac \\
\hline 0.0363 & 2.1404 & 1.3877 & 1.3810 & 1.3854 & 0.0044 & $\mathrm{Ac}$ \\
\hline 0.0397 & 2.3545 & 1.5139 & 1.3838 & 1.3903 & 0.0065 & N.Ac \\
\hline 0.0430 & 2.5685 & 1.6400 & 1.3855 & 1.3952 & 0.0097 & N.Ac \\
\hline 0.0463 & 2.7825 & 1.7662 & 1.3875 & 1.4002 & 0.0127 & N.Ac \\
\hline \multicolumn{7}{|c|}{ water (1) + methanol (2) + NaCl (3) } \\
\hline 0.0137 & 0.7803 & 0.6421 & 1.3402 & 1.3394 & 0.0008 & $\mathrm{E}$ \\
\hline 0.0203 & 1.1704 & 0.8562 & 1.3425 & 1.3416 & 0.0009 & E \\
\hline 0.0268 & 1.5605 & 1.0702 & 1.3447 & 1.3438 & 0.0009 & E \\
\hline 0.0332 & 1.9507 & 1.2842 & 1.3461 & 1.3461 & 0.0000 & $\mathrm{E}$ \\
\hline 0.0395 & 2.3408 & 1.4983 & 1.3475 & 1.3483 & 0.0008 & $\mathrm{E}$ \\
\hline 0.0456 & 2.7310 & 1.7123 & 1.3488 & 1.3505 & 0.0017 & $\mathrm{G}$ \\
\hline 0.0516 & 3.1211 & 1.9264 & 1.3506 & 1.3527 & 0.0021 & $\mathrm{Ac}$ \\
\hline 0.0574 & 3.5112 & 2.1404 & 1.3518 & 1.3549 & 0.0031 & Ac \\
\hline 0.0632 & 3.9014 & 2.3545 & 1.3538 & 1.3572 & 0.0034 & $\mathrm{Ac}$ \\
\hline 0.0688 & 4.2915 & 2.5685 & 1.3540 & 1.3594 & 0.0046 & $\mathrm{Ac}$ \\
\hline 0.0741 & 4.6816 & 2.9966 & 1.3555 & 1.3635 & 0.0080 & N.Ac \\
\hline 0.0848 & 5.4619 & 3.4247 & 1.3578 & 1.3680 & 0.0102 & N.Ac \\
\hline 0.0952 & 6.2422 & 3.8527 & 1.3597 & 1.3724 & 0.0127 & N.Ac \\
\hline 0.1051 & 7.0225 & 4.2808 & 1.3615 & 1.3769 & 0.0154 & N.Ac \\
\hline \multicolumn{7}{|c|}{ water (1) + ethanol (2) + NaCl (3) } \\
\hline 0.0048 & 0.2713 & 0.6421 & 1.3405 & 1.3395 & 0.0010 & $\mathrm{E}$ \\
\hline 0.0096 & 0.5427 & 0.8562 & 1.3435 & 1.3422 & 0.0013 & G \\
\hline 0.0142 & 0.8140 & 1.0702 & 1.3450 & 1.3449 & 0.0001 & $\mathrm{E}$ \\
\hline 0.0188 & 1.0853 & 1.2842 & 1.3461 & 1.3475 & 0.0014 & $\mathrm{G}$ \\
\hline 0.0233 & 1.3566 & 1.4983 & 1.3475 & 1.3502 & 0.0027 & Ac \\
\hline 0.0277 & 1.6280 & 1.7123 & 1.3488 & 1.3528 & 0.0040 & Ac \\
\hline 0.0320 & 1.8993 & 1.9264 & 1.3505 & 1.3555 & 0.0050 & Ac \\
\hline 0.0363 & 2.1706 & 2.1404 & 1.3529 & 1.3581 & 0.0052 & Ac \\
\hline 0.0405 & 2.4419 & 2.3545 & 1.3559 & 1.3608 & 0.0049 & Ac \\
\hline 0.0446 & 2.7133 & 2.5685 & 1.3548 & 1.3634 & 0.0086 & N.Ac \\
\hline 0.0527 & 3.2559 & 2.9966 & 1.3555 & 1.3687 & 0.0132 & N.Ac \\
\hline 0.0606 & 3.7986 & 3.4247 & 1.3578 & 1.3740 & 0.0162 & N.Ac \\
\hline 0.0682 & 4.3412 & 3.8527 & 1.3597 & 1.3793 & 0.0196 & N.Ac \\
\hline 0.0755 & 4.8839 & 4.2808 & 1.3615 & 1.3847 & 0.0232 & N.Ac \\
\hline \multicolumn{7}{|c|}{ water (1) + NaCl (2) + glycerol (3) } \\
\hline 0.0113 & 0.6421 & 0.8144 & 1.3461 & 1.3460 & 0.0000 & $\mathrm{E}$ \\
\hline 0.0149 & 0.8562 & 1.0859 & 1.3499 & 1.3503 & 0.0006 & E \\
\hline 0.0185 & 1.0702 & 1.3574 & 1.3538 & 1.3547 & 0.0010 & E \\
\hline 0.0220 & 1.2842 & 1.6288 & 1.3572 & 1.3590 & 0.0020 & $\mathrm{G}$ \\
\hline 0.0254 & 1.4983 & 1.9003 & 1.3602 & 1.3634 & 0.0033 & $\mathrm{Ac}$ \\
\hline
\end{tabular}




\begin{tabular}{|c|c|c|c|c|c|c|}
\hline 0.0288 & 1.7123 & 2.1718 & 1.3638 & 1.3677 & 0.0041 & $\mathrm{Ac}$ \\
\hline 0.0322 & 1.9264 & 2.4433 & 1.3679 & 1.3720 & 0.0044 & Ac \\
\hline 0.0355 & 2.1404 & 2.7147 & 1.3718 & 1.3764 & 0.0048 & $\mathrm{Ac}$ \\
\hline 0.0387 & 2.3545 & 2.9862 & 1.3761 & 1.3807 & 0.0049 & Ac \\
\hline 0.0419 & 2.5685 & 3.2577 & 1.3764 & 1.3850 & 0.0090 & N.Ac \\
\hline 0.0481 & 2.9966 & 3.8006 & 1.3796 & 1.3937 & 0.0145 & N.Ac \\
\hline 0.0541 & 3.4247 & 4.3436 & 1.3842 & 1.4024 & 0.0186 & N.Ac \\
\hline 0.0600 & 3.8527 & 4.8865 & 1.3857 & 1.4111 & 0.0258 & N.Ac \\
\hline 0.0657 & 4.2808 & 5.4295 & 1.3882 & 1.4197 & 0.0321 & N.Ac \\
\hline \multicolumn{7}{|c|}{ water (1) + sucrose (2) + $\mathrm{NaCl}(3)$} \\
\hline 0.0052 & 0.2921 & 0.4281 & 1.3491 & 1.3486 & 0.0005 & $\mathrm{E}$ \\
\hline 0.0065 & 0.3652 & 0.6421 & 1.3540 & 1.3535 & 0.0005 & $\mathrm{E}$ \\
\hline 0.0077 & 0.4382 & 0.8562 & 1.3589 & 1.3584 & 0.0005 & $\mathrm{E}$ \\
\hline 0.0090 & 0.5112 & 1.0702 & 1.3635 & 1.3632 & 0.0003 & $\mathrm{E}$ \\
\hline 0.0102 & 0.5843 & 1.2842 & 1.3680 & 1.3681 & 0.0001 & $\mathrm{E}$ \\
\hline 0.0114 & 0.6573 & 1.4983 & 1.3725 & 1.3730 & 0.0005 & $E$ \\
\hline 0.0126 & 0.7304 & 1.7123 & 1.3755 & 1.3779 & 0.0024 & $\mathrm{Ac}$ \\
\hline 0.0138 & 0.8034 & 1.9264 & 1.3796 & 1.3827 & 0.0031 & Ac \\
\hline 0.0150 & 0.8764 & 2.1404 & 1.3835 & 1.3876 & 0.0041 & Ac \\
\hline 0.0174 & 1.0225 & 2.3545 & 1.3906 & 1.3954 & 0.0048 & Ac \\
\hline 0.0197 & 1.1686 & 2.5685 & 1.3924 & 1.4032 & 0.0108 & N.Ac \\
\hline 0.0220 & 1.3146 & 2.9966 & 1.3981 & 1.4130 & 0.0149 & N.Ac \\
\hline 0.0242 & 1.4607 & 3.4247 & 1.4045 & 1.4227 & 0.0182 & N.Ac \\
\hline 0.0264 & 1.6068 & 3.8527 & 1.4095 & 1.4325 & 0.0230 & N.Ac \\
\hline
\end{tabular}

a: $\Delta n_{\mathrm{D}}^{\prime}=\left|n_{\mathrm{D}(\mathrm{exp})}-n_{\mathrm{D}(\text { calc })}\right|$

b: excellent (E): $0 \leq \Delta n_{D}{ }^{\prime} \leq 0.001 \quad ; \operatorname{good}(\mathrm{G}): 0.001 \leq \Delta n_{D}{ }^{\prime} \leq 0.002$

acceptable (Ac): $0.002 \leq \Delta n_{D} / \leq 0.005 ;$ not acceptable (N. Ac): $0.005 \leq \Delta n_{D}$ '

Table 4. The experimental and theoretical (obtained from Eq. 5) values of refractive index, $n_{\mathrm{D}}$, along with the comparison between them, R.C, for different quaternary solutions made by water, D- $(+)$-glucose monohydrate $(\mathrm{DGMH})$, sucrose, glycerol, ethanol, and sodium chloride $(\mathrm{NaCl})$ in wide range of mole fraction, $x_{2}$, and molal concentrations, $c$, at $\mathrm{T}=293.15 \mathrm{~K}$ and atmospheric pressure.

\begin{tabular}{|c|c|c|c|c|c|c|c|}
\hline$x_{2}$ & $\frac{c_{2}}{\mathrm{~mol} . \mathrm{Kg}^{-1}}$ & $\frac{c_{3}}{\text { mol. } \mathrm{Kg}^{-1}}$ & $\frac{c_{4}}{\text { mol. } \mathrm{Kg}^{-1}}$ & $n_{\mathrm{D}(\exp )}$ & $n_{\mathrm{D}(\mathrm{calc})}$ & $\Delta \boldsymbol{n}_{\mathbf{D}}^{\prime}$ & R.C \\
\hline \multicolumn{8}{|c|}{ water (1) + ethanol (2) + sucrose (3) + DGMH (4) } \\
\hline 0.0191 & 1.0853 & 0.1461 & 0.1262 & 1.3471 & 1.3447 & 0.0024 & Ac \\
\hline 0.0283 & 1.6280 & 0.2191 & 0.2523 & 1.3533 & 1.3520 & 0.0013 & $\mathrm{G}$ \\
\hline 0.0372 & 2.1706 & 0.2921 & 0.3785 & 1.3582 & 1.3593 & 0.0011 & $\mathrm{G}$ \\
\hline 0.0459 & 2.7133 & 0.3652 & 0.5046 & 1.3631 & 1.3667 & 0.0036 & Ac \\
\hline 0.0544 & 3.2559 & 0.4382 & 0.6308 & 1.3695 & 1.3740 & 0.0045 & Ac \\
\hline 0.0626 & 3.7986 & 0.5843 & 0.7569 & 1.3744 & 1.3842 & 0.0098 & N. Ac \\
\hline 0.0706 & 4.3412 & 0.7304 & 0.8831 & 1.3760 & 1.3945 & 0.0185 & N. Ac \\
\hline
\end{tabular}




\begin{tabular}{|c|c|c|c|c|c|c|c|}
\hline 0.0784 & 4.8839 & 0.8764 & 1.0092 & 1.3851 & 1.4048 & 0.0197 & N. Ac \\
\hline 0.0860 & 5.4265 & 1.0225 & 1.1354 & 1.3913 & 1.4150 & 0.0237 & N. Ac \\
\hline 0.0934 & 5.9692 & 1.1686 & 1.2615 & 1.3942 & 1.4253 & 0.0311 & N. Ac \\
\hline 0.1006 & 6.5118 & 1.3146 & 1.3877 & 1.3968 & 1.4355 & 0.0387 & N. Ac \\
\hline 0.1077 & 7.0545 & 1.4607 & 1.5139 & 1.4015 & 1.4458 & 0.0443 & N. Ac \\
\hline 0.1145 & 7.5971 & 1.6068 & 1.6400 & 1.4072 & 1.4561 & 0.0489 & N. Ac \\
\hline 0.1283 & 8.6824 & 1.7528 & 1.7662 & 1.4120 & 1.4677 & 0.0557 & N. Ac \\
\hline \multicolumn{8}{|c|}{ water (1) + ethanol (2) + sucrose (3) + glycerol (4) } \\
\hline 0.0190 & 1.0853 & 0.2921 & 0.2715 & 1.3512 & 1.3500 & 0.0012 & G \\
\hline 0.0280 & 1.6280 & 0.4382 & 0.5429 & 1.3581 & 1.3596 & 0.0015 & G \\
\hline 0.0368 & 2.1706 & 0.5843 & 0.8144 & 1.368 & 1.3693 & 0.0013 & $\mathrm{G}$ \\
\hline 0.0452 & 2.7133 & 0.7304 & 1.0859 & 1.3742 & 1.3790 & 0.0048 & Ac \\
\hline 0.0534 & 3.2559 & 0.8764 & 1.3574 & 1.3837 & 1.3887 & 0.0050 & $\mathrm{Ac}$ \\
\hline 0.0613 & 3.7986 & 1.0225 & 1.6288 & 1.3844 & 1.3984 & 0.0140 & N.Ac \\
\hline 0.0690 & 4.3412 & 1.1686 & 1.9003 & 1.3902 & 1.4081 & 0.0179 & N.Ac \\
\hline 0.0764 & 4.8839 & 1.3877 & 2.1718 & 1.3951 & 1.4207 & 0.0256 & N.Ac \\
\hline 0.0835 & 5.4265 & 1.6068 & 2.4433 & 1.4003 & 1.4333 & 0.0330 & N.Ac \\
\hline 0.0904 & 5.9692 & 1.8259 & 2.7147 & 1.4050 & 1.4459 & 0.0409 & N.Ac \\
\hline 0.0971 & 6.5118 & 2.0450 & 2.9862 & 1.4104 & 1.4585 & 0.0481 & N.Ac \\
\hline 0.1036 & 7.0545 & 2.2641 & 3.2577 & 1.4132 & 1.4711 & 0.0579 & N.Ac \\
\hline 0.1095 & 7.5971 & 2.4832 & 3.8006 & 1.4171 & 1.4862 & 0.0691 & N.Ac \\
\hline 0.1219 & 8.6824 & 2.7023 & 4.3436 & 1.4232 & 1.5026 & 0.0794 & N.Ac \\
\hline \multicolumn{8}{|c|}{ water (1) + $\mathrm{NaCl}(2)+$ sucrose (3) + glycerol (4) } \\
\hline 0.0038 & 0.2140 & 0.1461 & 0.2715 & 1.3464 & 1.3432 & 0.0032 & Ac \\
\hline 0.0076 & 0.4281 & 0.2191 & 0.5429 & 1.3530 & 1.3505 & 0.0025 & Ac \\
\hline 0.0112 & 0.6421 & 0.2921 & 0.8144 & 1.3585 & 1.3578 & 0.0007 & E \\
\hline 0.0148 & 0.8562 & 0.3652 & 1.0859 & 1.3669 & 1.3651 & 0.0018 & G \\
\hline 0.0183 & 1.0702 & 0.4382 & 1.3574 & 1.3715 & 1.3724 & 0.0009 & $\mathrm{E}$ \\
\hline 0.0218 & 1.2842 & 0.5112 & 1.6288 & 1.3782 & 1.3797 & 0.0015 & $\mathrm{G}$ \\
\hline 0.0252 & 1.4983 & 0.5843 & 1.9003 & 1.3822 & 1.3870 & 0.0048 & Ac \\
\hline 0.0285 & 1.7123 & 0.6573 & 2.1718 & 1.3893 & 1.3943 & 0.0050 & Ac \\
\hline 0.0318 & 1.9264 & 0.7304 & 2.4433 & 1.3913 & 1.4016 & 0.0103 & N.Ac \\
\hline 0.0350 & 2.1404 & 0.8764 & 2.7147 & 1.3955 & 1.4118 & 0.0163 & N.Ac \\
\hline 0.0381 & 2.3545 & 1.0225 & 2.9862 & 1.4006 & 1.4220 & 0.0214 & N.Ac \\
\hline 0.0411 & 2.5685 & 1.1686 & 3.2577 & 1.4061 & 1.4322 & 0.0261 & N.Ac \\
\hline 0.0441 & 2.7825 & 1.3146 & 3.5292 & 1.4112 & 1.4424 & 0.0312 & N.Ac \\
\hline
\end{tabular}

\section{Conclusions}

In this research work, the refractive indices for binary solutions of (methanol + glycerol) and (ethanol + glycerol) as well as ternary and quaternary solutions made by water, methanol, ethanol, glycerol, D-glucose monohydrate (DGMH), sucrose, and sodium chloride were determined in wide range of mole fractions at $\mathrm{T}=293.15 \mathrm{~K}$ and atmospheric pressure. Refractive indices data were correlated with equations 
that were suggested by Koohyar. These equations can be especially used in low (diluted solution) and middle concentrations of solutes. The value of constant of these equations $\left(K_{\mathrm{r}}\right)$, especially in binary solutions, can show the strength of interactions between solute and solvent molecules. Used equation

Obtained data can be used in pharmaceutical, food, detergent, and cosmetic industries. In addition, these data can help us to better understand interactions between species in these solutions.

\section{References}

1. Zuber, A., Checoni, R. F., Castier, R. Braz. J. Chem. Eng. 2015, 32, 637-646.

2. Gupta,V. K., Gupta, M., Sharma, S. Water. Res. 2001, 35, 1125-1134.

3. Anderko, A., Wang, P., Rafal, M. Fluid Phase Equilib. 2002, 194, 123-142.

4. Cui, W., Li, L., Guo, Y., Zhang, S., Deng. T. J. Chem., vol. 2018, Article ID 7962739, 4 pages, 2018. DOI.org/10.1155/2018/7962739.

5. Moreno, F. L., Raventós, M., Hernández, E., Santamaría, N., Acosta, J., Pirachican, O., Torres, L., Ruiz. Y. Int. J. Food Prop, 2015, 18, 426-438.

6. Koohyar, F. J. Thermodyn. Catal, 2013, 4, 1000e117 (Editorial).

7. Rosman, R., Dimon, M. N., Yeow, Y. K. Indones. J. Elctri. Eng \& Comput. Sci, 2018, 10, 853-858.

8. Bassey, C. E., Siguenza, C. A. Biophys. J., 2010, 98, Supplement 1, p 408a.

9. Liu, S., Zhao, Y., Parks, J. W., Deamer, D. W., Hawkins, A. R., Schmidt, H. Nano Lett, 2014, 14, 4816-4820.

10. Shen, F., Wang, J., Xu, Z., Wu, Y., Chen, Q., Li, X., Jie, X., Li, L., Yao, M., Guo, X., Zhu. T. Nano Lett, 2012, 12, 3722-3730.

11. DeSantis, M. C., Cheng, W. Wiley Interdiscip. Rev. Nanomed. Nanobiotechnol. 2016, 8, 717-729.

12. Pang, Y., Song, H., Cheng, W. Biomed. Opt. Express. 2016, 7, 1672-1689.

13. Mitra, A., Deutsch, B., Ignatovich, B., Dykes, C., Novotny, L. ACS Nano, 2010, 4, 1305-1312.

14. Mukundan, H., Anderson, A. S., Grace, W. K., Grace, K. M., Hartman, N., Martinez, J. S., Swanson, B. I. Sensors, 2009, 9, 5783-5809.

15. Yanik, A. A., Huang, M., Kamohara, O., Artar, A., Geisbert, T. W., Connor, J. H., Altug, H. Nano Letter. 2010, 10, 4962-4969.

16. Wang, S., Shan, X., Patel, U., Huang, X., Lu, J., Li, J., Tao, N. Proc. Natl. Acad. Sci. U.S.A. 2010, 107, 16028-16032.

17. Lu, T., Lee, H., Chen, T., Herchak, S., Kim, J. H., Fraser, S. E., Flagan, R. C., Vahala, K. Proc. Natl. Acad. Sci. U.S.A., 2011, 108, 5976-5979.

18. Zhu, H., White, I. M., Suter, J. D., Zourob, M., Fan, X. Analyst (Lond.), 2008, 133, 356-360.

19. Daaboul, G. G., Yurt, A., Zhang, X., Hwang, G. M., Goldberg, B. B., Ünlü, M. S. Nano Lett. 2010, 10, 4727-4731.

20. Vollmer, F., Arnold, S., Keng, D. Proc. Natl. Acad. Sci. U.S.A. 2008, 105, 20701-20704.

21. Block, O., Mitra, A., Novotny, L., Dykes, C. J. Virol. Methods. 2012, 182, 70-75.

22. Wade, J.H., Bailey, R. C. Anal. Chem, 2014, 86, 913-919.

23. Zhu, H., White, I. M., Suter, J. D., Zourob, M., Fan, X. Anal. Chem, 2007, 79, 930-937.

24. White, I. M., Oveys, H., Fan, X. Opt. Lett, 2006, 31, 1319-1321.

25. Suter, J. D., White, I. M., Zhu, H., Fan, X. Appl. Opt, 2007, 46, 389-396.

26. Lakshmi, K., Rajesh, T. Eur. J. Chem, 2010, 1, 262-265.

27. Riazi, M. R., Roomi, Y. A. Ind. Eng. Chem. Res, 2001, 40, 1975-1984.

28. Grodowska, K., Parczewski, A. Acta. Poloniae. Pharmaceutica. Drug Research, 2010, 67, 3-12.

29. Ballesteros, L. F., Teixeira, J. A., Mussatto, S. I. Food Bioprocess Technol, 2014, 7, 1322-1332.

30. Jiang, X., Wang, Y., Li, M. Sci. Rep, 2014, 4: 6070, 1-4. 
31. Bocho-Janiszewska, A., Wasilewski, T. Tenside, Surfactants, Deterg, 2017, 54, 372-376.

32. Szymanowska-Powałowska, D. Electron. J. Biotechnol, 2014, 17, 322-328.

33. Koohyar, F., Rostami, A. A., Chaichi, M. J., Kiani, F. J. Solution Chem, 2011, 40, 1361-1370.

34. Koohyar, F., Kiani, F. Iran. J. Chem. Chem. Eng, ASAP.

35. Lide, D.R. CRC handbook of Chemistry and Physics, 84th Edition, CRC Press, USA (2003-2004).

36. Koohyar, F., Kiani, F., Sharifi, S., Sharifirad, M., Rahmanpour, S. H. Res. J. Appl. Sci. Eng \& Technol, 2012, 4, 3095-3101.

37. Redlich, O., Kister, A. T. Ind. Eng. Chem, 1948, 40, 345-348.

38. Ribeiro, A. F., Langa, E., Mainar, A. M., Pardo, J. I., Urieta, J. S. J. Chem. \& Eng. Data, 2006, 51, 1846-1851. 